\title{
Child language assessment and intervention in multilingual and multicultural South Africa: Findings of a national survey
}

\author{
Ondene van Dulm \\ Department of Communication Disorders, University of Canterbury, Christchurch, New Zealand, Private Bag \\ 4800, Christchurch, 8140, New Zealand; and Department of General Linguistics, Stellenbosch University \\ Email: ondene.vandulm@,canterbury.ac.nz \\ Frenette Southwood \\ Department of General Linguistics, Stellenbosch University, Private Bag X1, Matieland, 7602, South Africa \\ Email: fs@sun.ac.za
}

\begin{abstract}
Research worldwide suggests that service delivery by speech-language therapists (SLTs) to bilingual children is problematic and largely unsatisfactory. In multicultural South Africa, the majority of SLTs speak either only English or only Afrikaans and English. The current state of service delivery to bilingual children, including those with first languages other than English or Afrikaans, is not known. This study was undertaken to ascertain how SLTs in South Africa adapt their assessment and intervention practices to cope with the multilingual and multicultural nature of the local child population. A questionnaire was completed by 243 practising SLTs who had children on their caseloads. $71 \%$ of respondents reported treating children with English as first language, 51\% Afrikaans, and 53\% an indigenous African language. Less than $2 \%$ reported not treating bilingual children. Almost all respondents could assess clients in English, 67\% in Afrikaans, and 15\% in an African language. A quarter could treat clients in one language only; $11 \%$ could do so in more than two languages. Only $7 \%$ reported that $90-100 \%$ of their bilingual clients receive intervention in their first language. $70 \%$ of respondents needed intervention material in English, 57\% in Afrikaans, and 33\% in an African language. $78 \%$ considered the underlying linguistic base when selecting a language assessment instrument; only $6 \%$ considered its linguistic and cultural appropriateness for use locally. The use of translations of English-medium instruments when assessing Afrikaansspeaking children was widely reported, as was dissatisfaction with standardised English- and Afrikaans-medium instruments. The findings supply essential information on the state of service delivery to bilingual children: After almost two decades of official multilingualism in South Africa, SLTs' practices remain a poor reflection of the multilingual and multicultural realities of the population. Steps toward improving the situation would include training more multilingual SLTs, specifically speakers of African languages, and expanding research leading to linguistically and culturally appropriate assessment and intervention material.
\end{abstract}

Keywords: child language assessment, child language intervention, survey, Afrikaans, African languages 


\section{Background}

Worldwide, the landscape in which speech-language therapy services are being provided is changing. The caseloads of speech-language therapists (SLTs) in previously culturally fairly homogenous countries in which a limited number of bilinguals ${ }^{1}$ required their services are becoming steadily more multicultural and multilingual. Europe, where immigration has tripled in the past half century (European Union 2013), is a case in point. Such immigration is leading to increasingly multilingual school populations in officially monolingual countries like Austria and Greece (European Union 2013). In countries like the United States of America (USA), where SLTs working in schools have had a bilingual clientele for many decades, there are indications that SLT services rendered to bilingual populations are less than satisfactory. For example, in a 2011 American Speech-Language-Hearing Association (ASHA) survey on health care (ASHA 2011), only 31\% of the respondents indicated that they were qualified to serve multicultural populations. Other surveys conducted in the USA focusing on issues of multilingualism and multiculturalism include that of Kritikos (2003) on beliefs held by SLTs regarding language assessment among bilingual/bicultural clients, in which most respondents reported low efficacy in bilingual assessment, with $40 \%$ of respondents indicating that they would be more conservative in recommending language intervention for a bilingual than a monolingual child, particularly due to their own lack of knowledge regarding bilingual issues.

In the United Kingdom (UK), Lindsay, Soloff, Law, Band, Peacey, Gascoigne and Radford's (2002) survey of 133 SLT managers found that provision of bilingual SLT services in England and Wales was limited, despite a growing bilingual child population (see Stow and Dodd 2003). Winter's (1999) survey conducted in England indicated a lack of information about bilingual children amongst SLTs and that the majority of SLTs (59\%) who work with children in officially monolingual England see at least one bilingual child. Mennen and Stansfield's (2006) survey of SLTs in English and Scottish cities indicated that there was not a disproportionately high representation of bilingual speakers on the caseloads of the SLTs surveyed, but the authors point out that "actual levels of service delivery go beyond simply appearing on a caseload" (2006:648). Considering that at least 35 languages other than English were represented on the caseloads of the 21 respondents to the survey, it is unlikely that many of the bilingual children concerned received services in a language other than English.

Consequences of the proliferation of bilingual clients on SLTs' caseloads around the world are highlighted by a survey undertaken by the Multilingual Affairs Committee of the International Association of Logopaedics and Phoniatrics and reported by Jordaan (2008). The survey investigated intervention practices with bilingual children among 99 SLTs across 13 countries. Findings indicated that very few therapists were providing bilingual intervention, and that there was a distinct lack of assessment materials for bilinguals, preventing SLTs from providing quantifiable intervention results.

South Africa is a richly multilingual country with 11 official languages, other indigenous South African languages without official status, and a growing number of languages spoken by immigrants from the rest of Africa and elsewhere. As pointed out by Barratt, Khoza-

\footnotetext{
${ }^{1}$ The term "bilingual" is used here to refer to bilingual and multilingual persons.
} 
Shangase and Msimang (2012), SLTs working in contexts of such cultural and linguistic diversity face immense challenges in their efforts to provide equitable services to all of their clients. The question arises as to what SLTs in South Africa are doing in practice to provide possible solutions to language barriers in the clinical arena. In order to address this question, the national survey reported upon in this paper was conducted amongst practising SLTs, focusing on the area of child language, and aiming to investigate whether and how SLTs in South Africa adapt their child language assessment and intervention practices to cope with the multilingual and multicultural nature of the South African population. In terms of general SLT practices, the present study also aimed to establish which child language assessment instruments are used by South African SLTs, the reasons for their use, and SLTs' level of satisfaction with these instruments. It is widely acknowledged that there is a general lack of assessment instruments designed for and standardised on South African children (see Penn 1998). The language skills of English-speaking South African children are usually assessed with British or American instruments, with or without replacement of inappropriate vocabulary items with ones appropriate for South African English. There are few instruments available for use with South Africans who speak a language other than English. Three instruments exist for Afrikaans, and there are also a small number of translations of assessment instruments into South African languages, such as the Northern Sotho version of the Peabody Picture Vocabulary Test - Revised (see Pakendorf and Alant 1997) and the Afrikaans and Xhosa versions of the Test of Auditory Comprehension of Language (see Leggo 1992). However, language assessment instruments that are linguistically and culturally appropriate for use in the South African context remain scarce, with most official languages not being represented at all. This need for appropriate assessment instruments designed for and standardised on child speakers of South African languages was central to our motivation to ascertain which assessment instruments are used by SLTs with these children, and why ${ }^{2}$. Finally, the survey reported here also investigated South African SLTs' needs for therapy material in any particular language, so as to ascertain what SLTs require post-assessment to deliver appropriate services to the multilingual child population.

\section{Aims}

The aim of the present survey was to gather data to inform the following questions with regard to SLTs practising among children with language problems in South Africa:

(i) What proportion of SLTs offer services to bilingual children?

(ii) In what languages do bilingual children receive intervention and in what languages is intervention material needed?

(iii) Which assessment instruments are favoured by South African SLTs, and how do they rate their satisfaction with available instruments?

\footnotetext{
${ }^{2}$ As noted by a reviewer, the fact that there is a need for appropriate assessment instruments for culturally and linguistically diverse populations is not a new concept in the global arena, and much has been done to address bias in assessment and remediation for children from such backgrounds. However, in the South African (and greater African) context, there remains a need to educate SLTs about the dangers (ethical as well as clinical) of using assessment instruments and remediation materials which are not linguistically and culturally appropriate for a particular child, and about ways in which the lack of appropriate assessment instruments and remediation materials may be addressed.
} 


\section{Method}

\subsection{The questionnaire}

The questionnaire used in this survey was devised by the authors to gather data to address the questions set out in section 2. The first section of the questionnaire requested respondents to indicate their names (optional), clinical setting/s and length of service delivery, and language skills, particularly the language/s in which they were able to evaluate and treat clients. The second section posed questions about respondents' clientele, particularly how many children with language problems typically existed on respondents' caseloads, the ages and first languages of the children, the proportion of the children who were bilingual, and how many of the children received intervention in their first (or "strongest") language. The third section focused on the assessment of and intervention for language problems, specifically the assessment instruments used and respondents' ratings of these in terms of various factors; the factors considered by respondents when selecting an assessment instrument; and the language/s in which intervention material is needed.

The questionnaire contained different types of questions. Content questions required written answers, such as the number of years spent working as a SLT in South Africa. Response selection questions offered a number of possible response categories, of which respondents could tick either one or more than one. For example, when asked to indicate the average number of children with language problems on their caseloads, respondents could tick only one of several categories $(1-5 ; 6-10 ; 11-15 ; 16-20 ; 20+)$, but when asked in which setting they work, respondents could tick one or more of the categories provided. For questions with an "Other" option, respondents were requested to supply further written information. Completion of the questionnaire took approximately 15 minutes.

\subsection{Respondents}

Paper copies of the questionnaire were posted to all of the 1915 SLTs registered with the Health Professions Council of South Africa (HPCSA) at the end of January 2012. (Note that such registration is a requirement for practising as a SLT in South Africa, but that not all registered SLTs do indeed practise. This means that every SLT practising in South Africa was sent a questionnaire, but that some recipients of the questionnaire would have been inactive in the field and would therefore have disregarded the questionnaire.) Fifty-eight questionnaires were returned undelivered, and 272 completed questionnaires were returned in the stamped, self-addressed envelopes provided, which comprises a return rate of $15 \%$. This response rate is low relative to similar survey studies carried out in developed countries, such as the USA, where a 1997 survey by Kemp and Klee of language sampling practices among SLTs yielded a 55\% response rate, a 2003 survey by Kritikos of SLTs' beliefs about bilingual and bicultural assessment yielded a 44\% response rate, and a 2007 survey by Skahan, Watson and Lof of assessment procedures used by SLTs for children with speech sound disorders yielded a 33\% response rate. The relatively low response rate in the present study may be due to (i) the possibility of non-practising SLTs not returning the questionnaire (as explained above), (ii) non-purposive sampling, as it was logistically not possible to send the survey to only those SLTs who treat child clients, and (iii) the authors, unlike some others, not sending out a reminder and thus not allowing for a second opportunity to complete the questionnaire. The response rate of $15 \%$ does raise the issue of how representative the obtained responses are of 
the general South African SLT population, but it compares favourably to that of the Pascoe, Maphalala, Ebrahim, Hime, Mdladla, Mohamed and Skinner (2010) study. These authors reported a response rate of $18.7 \%$ to their survey of clinical practices for children with speech difficulties in the Western Cape.

Of the 272 respondents in the present study, the data from 29 (11\% of the respondents) were omitted from the analysis presented below. These included nine respondents with dual HPCSA-registration who worked as audiologists only, five who were retired or inactive SLTs, 13 who were active SLTs but who did not have any children with language problems on their caseloads, one who saw children only in the course of her research (i.e. as participants, not as clients), and one who had a South African address but worked in a neighbouring country. The data presented below are drawn from the questionnaires completed by those 243 South Africa-based, HPCSA-registered SLTs who had children with language problems on their caseloads.

\subsection{Data analysis}

Data were transferred from the paper versions of the returned questionnaires to a Microsoft Office Excel file. Content analysis was used for the open responses and for unsolicited information in response to certain questions. Quantitative analysis entailed the tallying of responses for each response category and the calculation of a percentage out of the total possible responses. For example, for both single- and multiple-response selection questions such as the average number of children with language problems on their caseloads (singleresponse) - the percentage of responses in each category was calculated out of a total of 243 . However, some percentages had to be calculated out of a different total; for example, only 238 respondents indicated which assessment instruments they used routinely, so percentages pertaining to this part of the questionnaire were calculated out of 238 .

\subsection{Ethical clearance}

Ethical clearance for conducting the research was granted by the Ethics Committee of the Faculty of Arts and Social Sciences at Stellenbosch University. The questionnaire began with a paragraph informing respondents that the survey formed part of a research project investigating the state of child language assessment and intervention in South Africa; that participation was voluntary; that they could leave any question/s unanswered should they prefer to do so; that they could choose to remain anonymous, and that all information would be treated as confidential. Respondents were also given the opportunity to contact the authors with any questions or comments. Respondents who completed and returned the questionnaire thereby indicated their consent to participation in the survey.

\section{Findings and discussion}

\subsection{Language/s in which SLT services can be delivered}

Two hundred and forty-one of the 243 respondents (99\%) reported being able to evaluate their clients in English, 162 (67\%) in Afrikaans, and 37 (15\%) in an African language. Of the 32 respondents who specified in which African languages they were able to evaluate clients, 22 
indicated that they could do so in Zulu, seven in Tswana, six each in Xhosa and Sotho ${ }^{3}$, two in Swati, and one each in Ndebele, Shangaan, and Venda. Sixty-three respondents $(26 \%)$ indicated that they could evaluate clients in one language only. In one instance, that language was Venda; the other 62 respondents could evaluate clients in English only. The remaining 180 respondents $(74 \%)$ could evaluate clients in at least two languages; 22 respondents $(9 \%)$ could do so in at least three South African languages. These figures compare somewhat favourably to those of the Kritikos (2003) survey (carried out in five states of the USA) in which the majority of SLTs reported that they were not at all or only somewhat competent in the assessment of certain bilingual clients, even when making use of an interpreter.

With regard to the languages in which respondents could provide intervention, the figures were much the same as those reported above for assessment: 242 respondents $(99.6 \%)$ indicated that they could provide intervention in English, 162 (67\%) in Afrikaans, and 31 $(13 \%)$ in an African language. Sixty-two respondents (26\%) indicated that they could provide intervention in English only, 153 respondents (63\%) in two languages, and $27(11 \%)$ in more than two languages. These figures suggest that SLTs practising in South Africa are reasonably well-equipped to serve bilingual children bilingually (three-quarters can do so), but only (i) in terms of their language abilities (respondents were not asked about their clinical skills or confidence levels), and (ii) in certain language pairs, with English-Afrikaans being wellrepresented, but African languages decidedly poorly. Given the large number of African languages spoken in South Africa and the fact that many respondents who indicated that they can serve clients in an African language specified only one or a limited number of these languages, it appears that very few cases remain in which a SLT is able to serve a speaker of an African language in his/her language.

The finding for the number of respondents who can provide SLT services in English is comparable to that of Jordaan and Yelland (2003), who report that all of the respondents in their South African survey were fluent in English. However, the percentage of respondents in the present study who reported being able to provide services in an African language (15\%) was lower than that in the Jordaan and Yelland study (25\%). What is striking here is the disparity between the languages in which South African SLTs can provide services and the demographics of the country in terms of language. Fifteen per cent of the present respondents could serve clients in an African language, yet at least $78 \%$ of South Africans speak an African language as their home language (Statistics South Africa 2003).

Respondents were also asked about the languages in which they require child language therapy material. One hundred and seventy of the 243 respondents $(70 \%)$ indicated that they were in need of additional therapy material in English, 138 (57\%) in Afrikaans, and 80 (33\%) in an African language, specifically Zulu (29 respondents), Xhosa (14), Tswana (12), Sotho (11), and Swati and Venda (2 each). The data in Table 1 reflect the number of respondents providing intervention in a particular language in relation to the number of respondents expressing a need for intervention material in that language 4 .

\footnotetext{
${ }^{3}$ Although Southern Sotho/Sesotho and Northern Sotho/Sepedi/Pedi are two distinct languages, we group them together here, as some respondents indicated only "Sotho", which plausibly refers to Sesotho, but the possibility that "Northern Sotho" was meant could not be eliminated.

4 The figures indicating SLTs' needs for therapy materials in particular languages cannot, in the South African context, be seen merely as a suggestion that clinics and other institutions employing SLTs are poorly
} 
Table 1. Languages in which intervention can be provided and in which therapy material is needed

\begin{tabular}{lcc}
\hline Language & $\begin{array}{c}\text { Number of respondents who can } \\
\text { provide intervention }(\mathrm{N}=243)\end{array}$ & $\begin{array}{c}\text { Number of respondents who require } \\
\text { therapy material }(\mathrm{N}=243)\end{array}$ \\
\hline English & 242 & 170 \\
Afrikaans & 162 & 138 \\
Zulu & 15 & 29 \\
Tswana & 6 & 12 \\
Xhosa & 4 & 14 \\
\hline
\end{tabular}

Of interest in Table 1 are the three rows pertaining to African languages. In contrast to the case for English and Afrikaans, the number of respondents who expressed a need for therapy material is greater than the number who reported being able to provide intervention in these languages. The question arises as to what the respondents envisaged doing with therapy material in a language in which they cannot provide intervention. One possibility is that, while these respondents do not currently provide intervention in these languages, they may be able to do so should they have access to appropriate language therapy material, possibly with the help of an interpreter or with additional language training in addition to the material.

\subsection{Caseload characteristics}

The 243 respondents who reported treating children with language problems did so across the whole age range (see Table 2). Almost one fifth of the respondents were involved in very early intervention, seeing children younger than two years, and the majority of the respondents saw pre-schoolers as well as primary school learners of all ages. Almost one fifth of respondents reported having children of high school age (older than 13 years) on their caseloads.

Table 2. Ages of child clients with language problems on respondents' caseloads

\begin{tabular}{lccccccc}
\hline \multirow{2}{*}{ Respondents } & \multicolumn{7}{c}{ Age range of child clients } \\
\cline { 2 - 8 } & $<2$ yrs & $2-3$ yrs & $4-5$ yrs & $6-7$ yrs & $8-9$ yrs & $10-13$ yrs & $>13$ yrs \\
\hline $\mathrm{N}$ & 45 & 134 & 195 & 210 & 150 & 98 & 45 \\
$\%$ & 19 & 55 & 80 & 86 & 62 & 40 & 19 \\
\hline
\end{tabular}

With regard to the first languages of the children with language problems represented on caseloads, 171 respondents $(71 \%)$ reported treating children with English as their first language, $123(51 \%)$ Afrikaans, and $129(53 \%)$ an African language, specifically Zulu (27 respondents; 11\%), Sotho (23; 9\%), Xhosa (19; 8\%), Tswana (17; 7\%), Venda (3 respondents), Swati (2 respondents), and Ndebele (1 respondent). Three respondents stated that their clients speak "any languages of the country" or "various" languages. Note that these figures, read in relation to those given in Table 1, give an indication of the extent to which speakers of African languages are treated in a language other than their first language (see also Table 4 below). For example, four respondents can treat children in Xhosa but 19 have

provisioned. Rather, it is a direct reflection of the serious lack of such materials in South African languages besides English and, to a lesser extent, Afrikaans. 
Xhosa-speaking children on their caseloads, and six can treat children in Tswana but 17 have Tswana-speaking children on their caseloads.

Respondents were also asked what proportion of the children with language problems on their caseloads was bi- or multilingual. The findings in response to this question, presented in Table 3, show that slightly more than half of all 236 respondents who answered this question indicated that only 0 to $10 \%$ of their child language clients were bilingual, possibly reflecting the fact that the majority of respondents worked in largely monolingual contexts, such as mainstream or special needs schools in which there is a single medium of teaching and learning (usually either English of Afrikaans). One quarter of the respondents indicated that more than $60 \%$ of their child clients were bilingual.

Table 3. Bilingual children with language problems on respondents' caseloads

\begin{tabular}{lcccccccccccc}
\hline \multirow{2}{*}{$\begin{array}{l}\text { Respon- } \\
\text { dents }\end{array}$} & \multirow{10}{*}{ Percentage of bilingual children } \\
\cline { 2 - 13 } & \multirow{2}{*}{0} & $1-$ & $11-$ & $21-$ & $31-$ & $41-$ & $51-$ & $61-$ & $71-$ & $81-$ & $91-$ \\
& & $10 \%$ & $20 \%$ & $30 \%$ & $40 \%$ & $50 \%$ & $60 \%$ & $70 \%$ & $80 \%$ & $90 \%$ & $100 \%$ \\
\hline $\mathrm{N}$ & 3 & 52 & 29 & 27 & 26 & 33 & 9 & 10 & 19 & 19 & 12 \\
$\%$ & 1 & 22 & 12 & 11 & 11 & 14 & 4 & 4 & 8 & 8 & 5 \\
\hline
\end{tabular}

Turning to the question of the percentage of their bilingual child clients with language problems who receive intervention in their first language, one quarter of the 226 respondents who answered this question indicated $10 \%$ or less (see Table 4$)$. Only 16 respondents $(7 \%)$ reported that up to $100 \%$ of these children received intervention in their first language. These findings are even more disquieting than those of Jordaan and Yelland (2003), who found that only $20 \%$ of their 25 South African respondents were treating bilingual children in their first language, and $12 \%$ in both languages, while the remaining majority $(68 \%)$ treated bilingual child clients in English (their second language) only. The higher incidence of first language and bilingual treatment in Jordaan and Yelland's study may be partially due to their purposive sampling procedure, which targeted SLTs who self-identified as treating bilingual clients.

Table 4. Bilingual child clients receiving intervention in their first language

\begin{tabular}{lccccccccccc}
\hline \multirow{2}{*}{$\begin{array}{l}\text { Respon- } \\
\text { dents }\end{array}$} & \multicolumn{10}{c}{ Percentage of bilingual children } \\
\cline { 2 - 27 } & \multirow{2}{*}{$0 \%$} & $1-$ & $11-$ & $21-$ & $31-$ & $41-$ & $51-$ & $61-$ & $71-$ & $81-$ & $91-$ \\
& & $10 \%$ & $20 \%$ & $30 \%$ & $40 \%$ & $50 \%$ & $60 \%$ & $70 \%$ & $80 \%$ & $90 \%$ & $100 \%$ \\
\hline $\mathrm{N}$ & 11 & 57 & 22 & 14 & 19 & 16 & 8 & 19 & 19 & 25 & 16 \\
$\%$ & 5 & 25 & 10 & 6 & 8 & 7 & 4 & 8 & 8 & 11 \\
\hline
\end{tabular}

\subsection{Language assessment instruments used and criteria in their selection}

A total of 203 respondents answered the questions pertaining to the factors they consider when selecting an assessment instrument, of whom 166 (79\%) indicated that they consider the instrument's underlying linguistic base, and 120 (59\%) that they consider logistics (such as the price of the instrument or its availability). Forty-six (23\%) indicated that they considered factors other than the linguistic base and logistics, and 39 of these specified such factors. These factors included the cultural and linguistic appropriateness of the instrument for the South African context (12 respondents), the age-appropriateness for the client concerned (7), 
the time required to administer the instrument (6), the ease of administration and/or scoring (4), and the comprehensiveness of the areas assessed by the instrument (3). These findings indicate that, besides logistics like availability (considered by $59 \%$ of the respondents), the underlying linguistic base of an assessment instrument is commonly considered (by almost $80 \%$ of respondents), but the cultural and linguistic appropriateness by relatively few $(6 \%)$.

In terms of the nature of the assessment instruments used, 212 respondents provided information, of whom 136 (64\%) indicated that they use commercially available assessment instruments; $4 \%$ of these exclusively used such instruments and did not supplement the test results by doing informal assessment. One hundred and seventy-nine respondents (84\%) indicated that they used self-devised assessment instruments, with $11(6 \%)$ of these not making use of any commercially available assessments. One hundred and eighty-seven of the 212 respondents (88\%) explicitly indicated that they made use of a combination of commercially available and self-devised assessment instruments.

\subsection{Assessment instruments used with English-speaking clients}

Two hundred and thirty-eight respondents indicated which assessment instruments they routinely used with English-speaking child clients. Of the 12 instruments listed in the questionnaire, self-devised informal assessment tools were a popular option with 134 respondents $(56 \%)$ reporting that they make use of such assessment. In contrast to the case for Afrikaans, however (see below), self-devised informal assessment tools were not the most popular assessment method - more respondents (151 of the 238 respondents; 63\%) reported using the Test of Auditory Comprehension of Language (TACL-3; Carrow-Woolfolk 1998) ${ }^{5}$. Figures for these and the remaining 10 instruments listed in the questionnaire are given in Table 5.

Table 5. Usage statistics for English assessment instruments listed in the questionnaire

\begin{tabular}{lcc}
\hline \multirow{2}{*}{ Assessment instrument } & \multicolumn{3}{c}{ Respondents indicating routine use } \\
\hline $\begin{array}{l}\text { Test of Auditory Comprehension of Language } \\
\text { (TACL-3; Carrow-Woolfolk 1998) }\end{array}$ & 151 & $63 \%$ \\
\hline Self-devised informal assessment tools & 134 & $56 \%$ \\
\hline $\begin{array}{l}\text { Clinical Evaluation of Language Fundamentals } \\
\text { (CELF-4; Semel, Wiig and Secord 2003) }\end{array}$ & 106 & $45 \%$ \\
\hline $\begin{array}{l}\text { Illinois Test of Psycholinguistic Abilities } \\
\text { (ITPA-3; Hammill, Mather and Roberts 2001) }\end{array}$ & 93 & $39 \%$ \\
\hline $\begin{array}{l}\text { Peabody Picture Vocabulary Test } \\
\text { (PPVT-4; Dunn and Dunn 2007) }\end{array}$ & 93 & $39 \%$ \\
\hline $\begin{array}{l}\text { Language Assessment, Remediation and Screening } \\
\text { Procedure } \\
\text { (LARSP; Crystal, Fletcher and Garman 1981) }\end{array}$ & 53 & $22 \%$ \\
\hline $\begin{array}{l}\text { Expressive One-Word Picture Vocabulary Test } \\
\text { (EOWPVT-4; Brownell 2010) }\end{array}$ & 37 & $16 \%$ \\
\hline
\end{tabular}

\footnotetext{
${ }^{5}$ The reference for the most recent edition of each test is given throughout this paper, although some respondents indicated using an older edition, and some did not indicate which edition was used.
} 


\begin{tabular}{lll}
\hline $\begin{array}{l}\text { Preschool Language Scales } \\
\text { (PLS-5; Zimmerman, Steiner and Pond 2011) }\end{array}$ & 20 & $8 \%$ \\
$\begin{array}{l}\text { Test for Reception of Grammar } \\
\text { (TROG-2; Bishop 2003) }\end{array}$ & 16 & $7 \%$ \\
\hline $\begin{array}{l}\text { Diagnostic Evaluation of Language Variation } \\
\text { (DELV; Seymour, Roeper, De Villiers and De Villiers }\end{array}$ & 6 & $3 \%$ \\
2005) & 4 & $2 \%$ \\
\hline $\begin{array}{l}\text { Preschool Language Assessment Instrument } \\
\text { (PLAI-2; Blank, Rose and Berlin 2003) }\end{array}$ & 0 & $0 \%$ \\
\hline $\begin{array}{l}\text { Communicative Development Inventories } \\
\text { Pethick and Reilly 1993) }\end{array}$ & 0 & \\
\hline
\end{tabular}

The relatively high percentage of respondents who indicated using the LARSP $(22 \%)$ is noteworthy in light of the finding of Kemp and Klee (1997) who surveyed SLTs in the USA regarding their language sampling and transcription practices, and found that $85 \%$ were employing language sample analysis, but that only 3\% were using the LARSP (and $48 \%$ were using other non-standardised means). As the respondents in the present survey did not mention using any other language sample analysis techniques, one may conclude that language sampling is employed to a lesser extent by South African SLTs than by their USA counterparts.

Apart from the 12 instruments listed in the questionnaire, respondents had the option of indicating other instruments they routinely used, and a total of 69 of such instruments were mentioned. Sixty of these were mentioned by fewer than $8 \%$ of the 155 respondents who answered this question. Those mentioned by more than $10 \%$ of the 155 respondents are given in Table 6.

Table 6. Usage statistics for English assessment instruments not listed in the questionnaire

\begin{tabular}{|c|c|c|}
\hline \multirow{2}{*}{ Assessment instrument } & \multicolumn{2}{|c|}{ Respondents indicating routine use } \\
\hline & $\mathrm{N}$ & $\%$ of 238 respondents \\
\hline $\begin{array}{l}\text { Test of Language Development } \\
\text { (TOLD-4; Newcomer and Hammill 2008) }\end{array}$ & 42 & $18 \%$ \\
\hline $\begin{array}{l}\text { Renfrew Language Scales } \\
\text { (RLS; Renfrew 1997) }\end{array}$ & 24 & $10 \%$ \\
\hline $\begin{array}{ll}\text { Specified as } & \text { Renfrew Action Picture Test } \\
& \text { Renfrew Word Finding Vocabulary Test } \\
& \text { Renfrew Bus Story }\end{array}$ & $\begin{array}{l}51 \\
16 \\
12\end{array}$ & $\begin{array}{c}21 \% \\
7 \% \\
5 \%\end{array}$ \\
\hline $\begin{array}{l}\text { Reynell Developmental Language Scales } \\
\text { (RDLS; Reynell and Gruber 1990) }\end{array}$ & 24 & $10 \%$ \\
\hline $\begin{array}{l}\text { Test of Auditory Processing Skills } \\
\text { (TAPS-3; Martin and Brownell 2005) }\end{array}$ & 18 & $8 \%$ \\
\hline The Pendulum Test ${ }^{6}$ & 17 & $7 \%$ \\
\hline
\end{tabular}

${ }^{6}$ The Pendulum is a test of phonological processing which tests aspects such as analysis and synthesis of words as well as working memory for digits. This assessment instrument is frequently used by certain South African SLTs, but its origin (and therefore its bibliographical details) remains untraceable by the authors. 


\subsection{Assessment instruments used with Afrikaans-speaking clients}

In the case of assessment instruments routinely used with Afrikaans-speaking clients, a list of 15 instruments, including the "own informal assessment" category, was once again provided in the questionnaire, and respondents were also requested to mention other, unlisted instruments they used routinely. One hundred and fifty-eight respondents answered this part of the questionnaire, amongst whom six of the 15 listed instruments were used by fewer than 10 respondents. These were (in decreasing order of use): an Afrikaans translation of the PLS, an Afrikaans translation of the TROG, the Toets vir Mondelinge Taalproduksie (TMT; "Test for Oral Language Production", Vorster 1980; one of the three language assessment instruments developed for use among and standardised on Afrikaans-speaking children), an Afrikaans translation of the PLAI, an Afrikaans translation of the DELV, and an Afrikaans translation of the CDI, the latter of which was indicated by no respondent, which is likely to be an indication that no such translation exists.

Of the remaining nine instruments listed in the questionnaire for use with Afrikaans-speaking children, the one used most was "Own informal assessment", by 123 of the 158 respondents (78\%), with 18 respondents (15\% of the 123) indicating that they made use of such assessment only. The reported routine use of the listed instruments is given in Table 7.

Table 7. Usage statistics for Afrikaans assessment instruments listed in the questionnaire

\begin{tabular}{|c|c|c|}
\hline \multirow{2}{*}{ Assessment instrument } & \multicolumn{2}{|c|}{ Respondents indicating routine use } \\
\hline & $\mathrm{N}$ & $\%$ of 158 respondents \\
\hline Self-devised informal assessment tools & 123 & $78 \%$ \\
\hline $\begin{array}{l}\text { Afrikaans translation of TACL-3 } \\
\text { (Carrow-Woolfolk 1998) }\end{array}$ & 90 & $57 \%$ \\
\hline $\begin{array}{l}\text { Afrikaanse Semantiese Taalevaluasiemedium } \\
\text { (Afrikaans Semantic Evaluation Medium; Pretorius 1989) }\end{array}$ & 57 & $36 \%$ \\
\hline $\begin{array}{l}\text { Afrikaanse Reseptiewe Woordeskattoets } \\
\text { (Afrikaans Receptive Vocabulary Test; Buitendag 1994) }\end{array}$ & 48 & $30 \%$ \\
\hline $\begin{array}{l}\text { Afrikaans translation of ITPA } \\
\text { (Hammill, Mather and Roberts 2001) }\end{array}$ & 48 & $30 \%$ \\
\hline $\begin{array}{l}\text { Afrikaans translation of PPVT } \\
\text { (Dunn and Dunn 2007) }\end{array}$ & 36 & $23 \%$ \\
\hline $\begin{array}{l}\text { Afrikaans version of LARSP } \\
\text { (Crystal, Fletcher and Garman 1981) }\end{array}$ & 28 & $18 \%$ \\
\hline $\begin{array}{l}\text { Afrikaans translation of CELF } \\
\text { (Semel, Wiig and Secord 2003) }\end{array}$ & 20 & $13 \%$ \\
\hline $\begin{array}{l}\text { Afrikaans translation of EOWPVT } \\
\text { (Brownell 2010) }\end{array}$ & 17 & $11 \%$ \\
\hline
\end{tabular}

A total of 37 instruments not listed in the questionnaire were also mentioned as being used routinely for Afrikaans-speaking children. These included Afrikaans translations of the RLS (29 respondents), of whom 17 specified that they used the Renfrew Action Picture Test, four the Renfrew Bus Story, and two the Renfrew Word Finding Vocabulary Test; the RDLS (12 respondents); the TOLD (12 respondents); and the Pendulum Test (7 respondents). A further 
30 other instruments were each mentioned by five or fewer respondents, of which 23 were mentioned by one respondent only.

As one might expect, given the lack of standardised assessment instruments available, the figures above suggest that SLTs serving Afrikaans-speaking children rely largely on selfdevised assessment material. They use such material either on its own $(15 \%$ of these respondents) or in addition to Afrikaans instruments, either developed in Afrikaans or translated from British or American English. On the one hand, such self-devised assessment material should be used with due caution as there is no control over their inter-user reliability and also no standardised basis for setting intervention goals based on their results. On the other hand, the use of self-devised assessment material is commendable because it shows an awareness on the side of South African SLTs that reliance on non-standardised translations is not clinically appropriate. However, the creation by SLTs of their own material should not divert the focus from the need for linguistically and theoretically well-founded assessment instruments standardised on Afrikaans-speaking children.

\subsection{Rating of commercially available assessment instruments}

Respondents were asked to provide information on the five commercially available assessment instruments that they use most frequently. Specifically, they were asked to (i) rate the efficacy of the instrument in terms of diagnosis on a four-point scale, (ii) rate its ability to provide intervention guidelines on a four-point scale, (iii) indicate what they liked about the instrument (given the options realistic purchase price, quick to administer, comprehensive, dialect-neutral, easy scoring, pictures appropriate for use in South Africa, and other-please specify), and (iv) indicate what they disliked about it (given the options time-consuming to administer, tests too few language skills, discriminates against speakers of nonstandard dialects, complicated scoring, some words/items inappropriate for use in South Africa, not all items are translatable, and other - please specify). A total of 73 instruments were rated by 229 respondents. The five instruments that were rated by more than 45 respondents are discussed here, in addition to two of the three instruments developed for use with and standardised on Afrikaans-speaking children. (As only one respondent rated the Toets vir Mondelinge Taalproduksie, the ratings for this instrument are not included here.) The ratings for diagnostic efficacy and provision of intervention guidelines are given in Figures 1 and 2, respectively.

With regard to the English-medium assessment instruments and their non-standardised Afrikaans translations, the figures indicate that most respondents rated them Good in terms of their efficacy in diagnosis, and Fair or Good in terms of their ability to provide intervention guidelines. A similar pattern emerged for the Afrikaans-medium instruments, with the diagnostic efficacy of the ARW receiving higher ratings than its ability to provide intervention guidelines, and the opposite relationship for the AST.

Turning to the aspects of the assessment instruments that the respondents noted as positive, the data are presented in Figure 3. Recall that the data presented here reflect respondents' indications of what they particularly liked about the instruments they used most frequently. No instrument scored well with regard to realistic purchase price, with the highest scores (around 20\%) being given for the AST and RLS. Note that the ARW (the Afrikaans vocabulary test) was regarded by far fewer respondents to be quick to administer than was the 


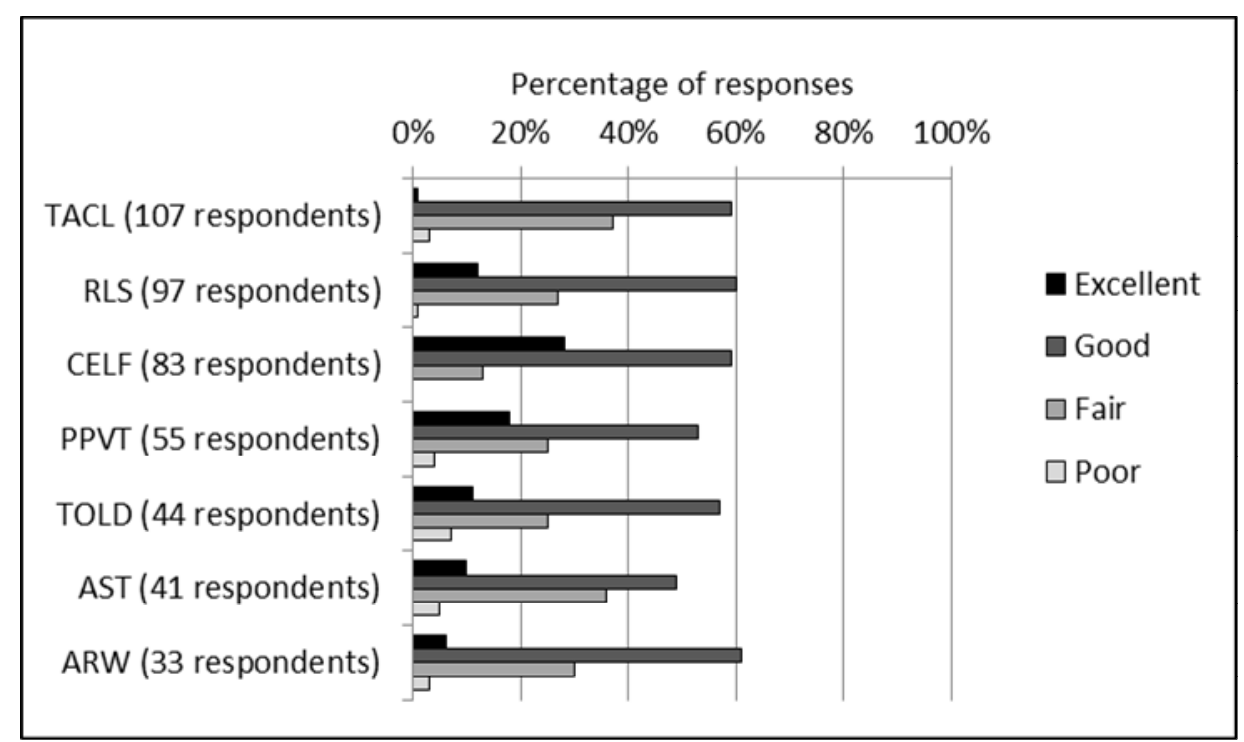

Figure 1. Ratings of instruments' diagnostic efficacy

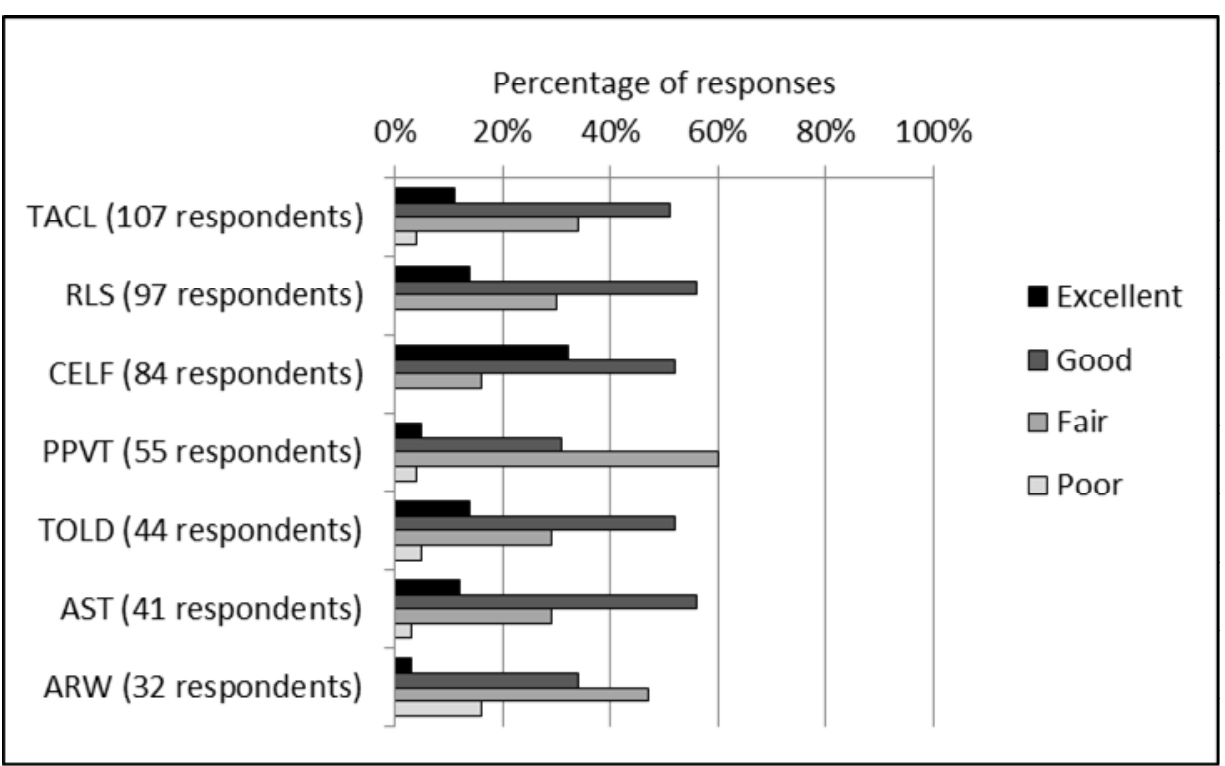

Figure 2. Ratings of instruments' ability to provide intervention guidelines

PPVT (an English vocabulary test): $52 \%$ vs. $78 \%$ of respondents in this regard. Just over half of the respondents indicated that the TACL was quick to administer, and just under half the TOLD, whereas only one quarter of the respondents indicated that the CELF was quick to administer. It may be assumed that the judgment of being "quick" is made relative to the nature and extent of information provided by the instrument. Note in this regard that the CELF was indicated by over $80 \%$ of respondents to be comprehensive, and that, as might be expected, the instruments addressing a range of language skills (including the AST for Afrikaans), scored higher for being comprehensive than did the vocabulary tests (e.g. ARW and PPVT). Not one of the instruments was frequently indicated to be dialect-neutral - the RLS (with 30\%) outperformed the other instruments on this measure. Whereas this is perhaps not unexpected for the instruments developed for USA and UK populations, it is a concern for the AST and ARW which were developed for the South African Afrikaans-speaking population, but perhaps remain less appropriate for speakers of non-standard dialects. In terms 
of ease of scoring, every instrument presented in Figure 3 was indicated as being easy to score by more than half of the respondents. Finally, in terms of the appropriateness of pictures for the South African context, all the instruments received positive ratings from less than $53 \%$ of the respondents. It is noteworthy that the RLS (with 47\%) compared favourably to the Afrikaans instruments in this regard, namely the ARW (with 52\%) and the AST (with 46\%), and it is, once again, disconcerting to note that the two assessment instruments developed for use in South Africa were not rated higher in terms of appropriateness of picture material.

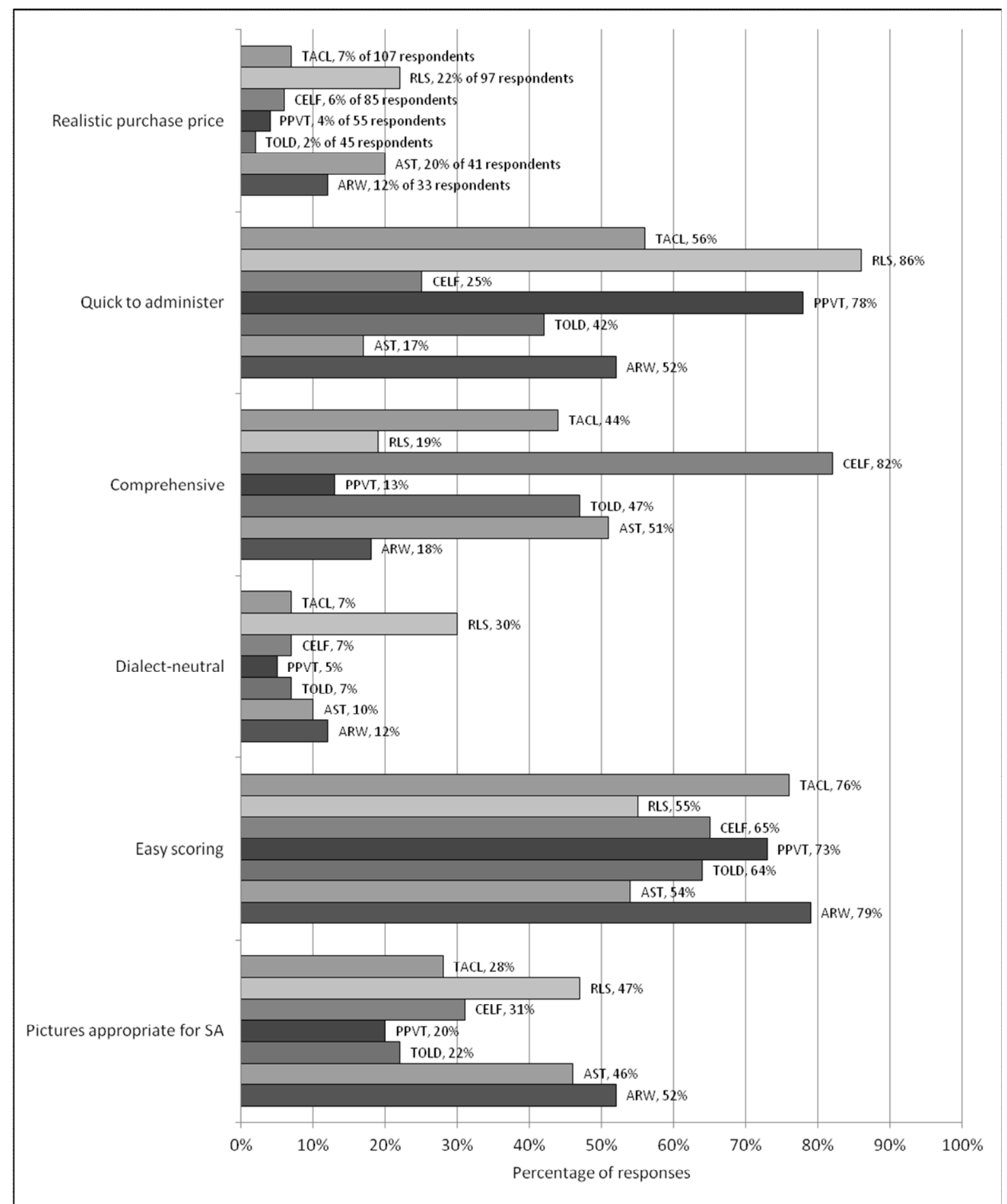

Figure 3. Positive aspects of assessment instruments 
The data on the aspects of assessment instruments which respondents reported disliking are presented in Figure 4. In terms of being time-consuming to administer, the CELF and the AST were most frequently indicated. The instrument viewed by the fewest respondents to be time-consuming was the PPVT. These findings are to be expected, as is the finding that the PPVT was most frequently indicated as assessing too few language skills. Note that all of the instruments scored between $21 \%$ and $36 \%$ in terms of assessing too few skills, with only the CELF (at 6\%) being an outlier. This finding is predictable to an extent, but is perhaps a concern for other English-language instruments like the TOLD, and certainly seems to suggest a need for such a broad-based instrument for the Afrikaans-speaking population, which is as comprehensive in its treatment of language as the CELF is. In terms of discriminating against speakers of non-standard dialects, it is encouraging to note that the AST scored the lowest (15\% of respondents). The ARW falls around the middle, and no instrument was indicated by more than one third of respondents to show such discrimination. The RLS was the instrument indicated by the highest number of respondents to have a complicated scoring system, but this was still relatively low at $21 \%$. The PPVT was the instrument most frequently indicated to contain words or pictures inappropriate for use in the South African context - almost three-quarters of the respondents indicated that they disliked this about the PPVT. The TOLD, TACL, and CELF all scored relatively highly in this regard (despite the TACL and CELF being quite highly favoured by respondents according to the data in Table 5), and far higher than the South African-developed instruments, the AST and ARW, which is encouraging. In general, not many respondents indicated concern about the translatability of items in the instruments. The instrument that received the highest number of ratings for having untranslatable items was the TACL (37\%). Note that $5 \%$ and $6 \%$ of respondents indicated that the ARW and AST, respectively, contained untranslatable items, which leads to the question concerning the language/s into which South African SLTs might wish to translate these two Afrikaans-medium instruments.

In a survey conducted by Huang, Hopkins and Nippold (1997) among 216 SLTs in Oregon (USA) on their degree of satisfaction with several factors associated with language testing (namely time available for test administration and interpretation, funding available for purchasing assessment instruments, and psychometric properties of assessment instruments), it was found that approximately half of the respondents were neutral towards these aspects, and that the remaining half was almost evenly split between some degree of (dis)satisfaction. In the present survey, there was at least some dissatisfaction with all listed aspects of every English-medium standardised instrument, with the exception of scoring complexity of the PPVT which was not indicated by any respondent.

In summary, with regard to the critical evaluation of the various instruments by the respondents, note that at least $65 \%$ of the respondents liked at least one aspect and at least $25 \%$ of the respondents disliked at least one aspect of the five English-medium instruments; and at least $52 \%$ of the respondents liked at least one aspect and at least $41 \%$ of the respondents disliked at least one aspect of the two Afrikaans-medium instruments. 


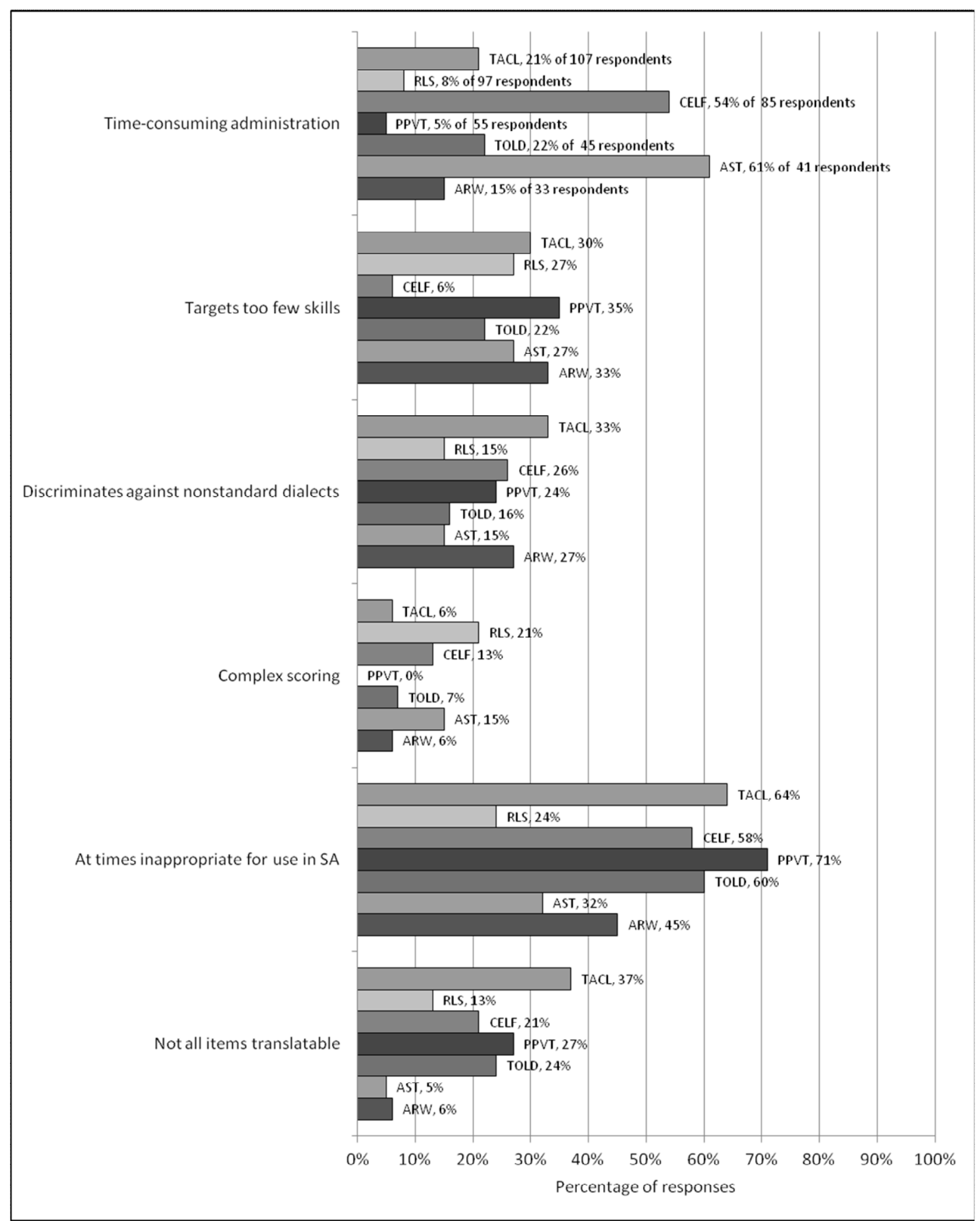

Figure 4. Negative aspects of assessment instruments

\subsection{Rating of therapy material}

Regarding commercially available therapy material, $47 \%$ of the 236 respondents who answered this part of the questionnaire indicated that they mostly found such material linguistically appropriate for use in the South African context (giving either a positive or strongly positive response on a four-point scale: Definitely agree, Agree to an extent, Don't 
really agree, Definitely disagree). The other $53 \%$ of the respondents indicated that they did not regard such material as linguistically appropriate, giving a negative or strongly negative response. Seventy-three respondents (31\%) reported mostly finding commercially available material culturally appropriate for use in South Africa; the majority $(163 ; 69 \%)$ reported the opposite. These findings suggest a relatively low level of satisfaction with the appropriateness of commercially available therapy material for the South African context, with just over half of respondents being dissatisfied with the linguistic appropriateness, and more than two-thirds with the cultural appropriateness. Considering that approximately three-quarters of the respondents indicated that more than $10 \%$ of the children on their caseloads were bilingual, it is encouraging to note that well over three-quarters of the respondents reported using selfdevised material as well as commercially available material. This indicates an awareness of the need for such home-grown solutions to the problem of a lack of linguistically and culturally appropriate material. However, this finding also strongly emphasises the need for SLTs to be educated about how to ensure that such self-devised material is linguistically and culturally appropriate for the client being treated.

\section{Conclusions and implications}

The general aim of the survey reported upon here was to investigate the child language assessment and intervention practices of South African SLTs in order to ascertain whether these practices reflect the multilingual and multicultural realities of the South African population. In particular, the survey aimed to gather information on the characteristics of the children with language problems seen by South African SLTs, the languages in which assessment and intervention is carried out, and the tools used and required for this assessment and intervention.

The responses obtained from the 243 respondents suggest that around one quarter of South African SLTs can provide services in English only, and that almost $75 \%$ are capable of working bi- or multilingually. Although English has one of the smaller home language bases in South Africa (8.2\% of the population has English as home language; Statistics South Africa 2003), English is the country's lingua franca and the dominant language in the domains of trade and industry, science and technology, politics, and education (De Wet 2002), with English being the language of learning and teaching of more than $90 \%$ of South African school children (Strauss, Van der Linde, Plekker and Strauss 1999). The question arises as to whether, if English is the preferred language in the domain of education, it matters that a quarter of South African SLTs cannot serve children in a language other than English. We believe that it does matter, as the English proficiency of many South African children is low (see Fleisch 2008) and, as clearly indicated in the 2011 Progress in International Reading Literacy Study (Mullis, Martin, Foy and Drucker 2012), their reading ability is decidedly poor. In order to disentangle a child who is a typically developing early English-speaking bilingual (who needs more and better quality English input in order to develop the required language skills to cope with English academically) from a bilingual English-speaking child with language impairment (who requires the services of a SLT), the SLT needs to determine whether the child's language skills in the other language are age-appropriate; a diagnosis of bilingual language impairment cannot be made on the assessment results of one language only (Jordaan and Yelland 2003). The high number of English-only SLTs and the low representation of languages other than English and Afrikaans amongst South African SLTs therefore remain disconcerting. 
The findings reported here indicate that South African SLTs see children with language problems who speak English, Afrikaans and/or an African language. In the case of some SLTs, up to $100 \%$ of their child clients are bilingual. The proportion of children who receive intervention in their first language varies widely: for one quarter of SLTs, this is $10 \%$ or less, and for one eighth, this is up to $100 \%$. Recall that Jordaan and Yelland (2003) found that $68 \%$ of surveyed South African SLTs were providing intervention in their clients' second language (which was English) only. Findings such as these indicate a dire need for more bilingual and/or African language-speaking SLTs in South Africa (see Southwood and Van Dulm, under review, for the language requirements of South African undergraduate training programmes for SLTs).

When assessing children's language abilities, South African SLTs appear to make use of a wide range of commercially available as well as self-devised assessment instruments, but few make routine use of language sample analysis. Approximately $70 \%$ of the present respondents consider the underlying linguistic base of the assessment instrument when selecting assessment instruments, which is encouraging insofar as it reflects adequate training in linguistics and its application to the clinical situation. Less encouraging is the mere 5\% who consider the cultural and/or linguistic appropriateness of the instrument for the South African context; however, this lack of reported consideration may be partly a reflection of the lack of available alternatives. Less than half of the present respondents regard commercially available instruments as linguistically appropriate for use in the South African context and only about one third as culturally appropriate. Apart from ease of scoring, the three standardised Afrikaans-medium instruments received few positive ratings, and there was little mention of African language versions of standardised instruments. These findings suggest that South African SLTs make use of commercially available assessment instruments mainly in English and Afrikaans, and of Afrikaans translations of UK- and USA-developed instruments, but that there are still very few instruments available (translated or otherwise) in other South African languages.

The reality of the South African SLT landscape goes beyond the question of whether SLTs are able to serve child clients in a language other than English. This question is somewhat moot if evidence-based, linguistically and culturally appropriate assessment instruments and intervention materials are not available to do so. While the training of more SLTs with South African languages other than English and Afrikaans as mother tongue, as well as the training of English- and Afrikaans-speaking SLTs in other South African languages, will go some way towards addressing the need for SLTs capable of treating bilingual children, such treatment is unlikely to be effective in the absence of a repository of assessment instruments and intervention materials that are either developed specifically for use with the South African population, or adapted from existing materials in a manner that takes cultural and linguistic issues into account.

On the basis of the findings of this survey, we conclude that, almost two decades after becoming an officially multilingual country, there is still a grave mismatch between the language profiles of South African SLTs and the material available to them for service delivery, on the one hand, and the multilingual and multicultural realities of South African society, on the other. The need for greater African language representation in the profession remains, as does the need for linguistically and culturally appropriate assessment and 
intervention materials. The progress made in meeting these needs since Penn's (1998) review and Jordaan and Yelland's (2003) survey appears somewhat disappointing, but the extent of research currently being conducted on child language development and its assessment among speakers of Afrikaans and African languages is encouraging (see Klop, Visser and Oosthuizen 2012, Pascoe and Smouse 2012, Southwood and Van Dulm 2009, Van Dulm and Southwood 2008). It is hoped that the findings reported here might spur on such developments, giving practising SLTs and researchers alike some direction by highlighting specific knowledge gaps and material development needs.

\section{References}

ASHA, Health Care Survey 2011: Caseload characteristics. Available online: http://www.asha.org/uploadedFiles/HC11-Caseload-Characteristics.pdf $\quad$ (Accessed 28 November 2012).

Barratt, J., K. Khoza-Shangase and K. Msimang. 2012. Speech-language assessment in a linguistically diverse setting: Preliminary exploration of the possible impact of informal 'solutions' within the South African context. South African Journal of Communication Disorders 59: 34-44.

Bishop, D.V.M. 2003. Test for reception of grammar. San Antonio: Pearson.

Blank, M., S.A. Rose and L.J. Berlin. 2003. Preschool language assessment instrument. Austin: Pro-Ed.

Brownell, R. 2010. Expressive one-word picture vocabulary test. San Antonio: Pearson.

Buitendag, M.M. 1994. Afrikaanse reseptiewe woordeskattoets [Afrikaans receptive vocabulary test]. Pretoria: Human Sciences Research Council.

Carrow-Woolfolk, E. 1998. Test for auditory comprehension of language. San Antonio: Pearson.

Crystal, D., P. Fletcher and M. Garman. 1981. Language assessment, remediation and screening procedure. Reading: University of Reading.

De Wet, C. 2002. Factors influencing the choice of English as language of learning and teaching (LOLT) - A South African perspective. South African Journal of Education 22: 119124.

Dunn, L.M. and D.M. Dunn. 2007. Peabody picture vocabulary test - Fourth edition. San Antonio: Pearson.

European Union. 2013. Study on educational support for newly arrived migrant children: Final report. Brussels: Publications Office of the European Union. 
Fenson, L., P.S. Dale, J.S. Reznick, D. Thal, E. Bates, J.P. Hartung, S. Pethick and J.S. Reilly. 1993. MacArthur communicative development inventories. Baltimore: Paul H. Brookes.

Fleisch, B. 2008. Primary education in crisis. Cape Town: Juta.

Hammill, D., N. Mather and R. Roberts. 2001. Illinois test of psycholinguistic abilities. Austin: Pro-Ed.

Huang, R.J., J. Hopkins and M.A. Nippold. 1997. Satisfaction with standardized language testing: A survey of speech-language pathologists. Language, Speech and Hearing Services in Schools 28: 12-29.

Jordaan, H. 2008. Clinical intervention for bilingual children: An international survey. Folia Phoniatrica et Logopaedica 60: 97-105.

Jordaan, H. and A. Yelland. 2003. Intervention with multilingual language impaired children by South African speech-language therapists. Journal of Multilingual Communication Disorders 1: 13-33.

Kemp, K. and T. Klee. 1997. Clinical language sampling practices: Results of a survey of speech-language pathologists in the United States. Child Language Teaching and Therapy 13: 161-176.

Klop, D., M. Visser and H. Oosthuizen. 2012. The Afrikaans adaptation of LITMUS-MAIN. ZAS Papers in Linguistics 56: 1-135.

Kritikos, E.P. 2003. Speech-language pathologists' beliefs about language assessment of bilingual/bicultural individuals. American Journal of Speech Language Pathology 12: 73-91.

Leggo, S. 1992. The revision and application of the Xhosa Test for the Auditory Comprehension of Language (XTACL). Stellenbosch: University of Stellenbosch.

Lindsay, G., N. Soloff, J. Law, S. Band, N. Peacey, M. Gascoigne and J. Radford. 2002. Speech and language therapy services to education in England and Wales. International Journal of Language and Communication Disorders 37: 273-288.

Martin, N. and R. Brownell. 2005. Test of auditory processing skills. Novato: Academic Therapy Publications.

Mennen, I. and J. Stansfield. 2006. Speech and language therapy service delivery for bilingual children: A survey of three cities in Great Britain. International Journal of Language and Communication Disorders 41: 635-652.

Mullis, I.V.S., M.O. Martin, P. Foy and K.T. Drucker. 2012. PIRLS 2011 International results in reading. Chestnut Hill: TIMSS and PIRLS International Study Center.

Newcomer, P.L. and D.D. Hammill. 2008. Test of language development - Primary and intermediate. Austin: Pro-Ed. 
Pakendorf, C. and E. Alant. 1997. Culturally valid assessment tools: Northern Sotho translation of the Peabody Picture Vocabulary Test - Revised. The South African Journal of Communication Disorders 44: 3-12.

Pascoe, M., Z. Maphalala, A. Ebrahim, D. Hime, B. Mdladla, N. Mohamed and M. Skinner. 2010. Children with speech difficulties: An exploratory survey of clinical practice in the Western Cape. South African Journal of Communication Disorders 57: 66-75.

Pascoe, M. and M. Smouse. 2012. Masithethe: Speech and language development and difficulties in isiXhosa. South African Medical Journal 102: 469-471.

Penn, C. 1998. The study of child language in South Africa. Folia Phoniatrica et Logopaedica 50: 256-270.

Pretorius, A. 1989. Afrikaanse semantiese taalevalueringsmedium [Afrikaans semantic language evaluation medium]. Pretoria: A. Pretorius.

Renfrew, C. 1997. Renfrew language scales. Milton Keynes: Speechmark Publishing.

Reynell, J.K. and C.P. Gruber. 1990. Reynell developmental language scales. Torrance: Western Psychological Services.

Semel, E., E.H. Wiig and W.A. Secord. 2003. Clinical evaluation of language fundamentals. San Antonio: Pearson.

Seymour, H.N., T. Roeper, J. de Villiers and P. de Villiers. 2005. Diagnostic evaluation of language variation (DELV) - Norm referenced. San Antonio: Pearson.

Southwood, F. and O. van Dulm. (under review). The challenge of linguistic and cultural diversity: Does length of experience affect South African speech-language therapists' management of children with language impairment? Submitted to South African Journal of Communication Disorders.

Southwood, F. and O. van Dulm. 2009. Die poeliesman het 'n gun: Die prestasie van Kaapssprekende plattelandse leerders op 'n Afrikaans-medium taaltoets wat dialek-neutraal sou wees. [The policeman has a gun: The performance of "Kaaps"-speaking rural learners in a purportedly dialect-neutral Afrikaans-medium language]. Litnet Akademies 6: 1-15.

Statistics South Africa. 2003. Census 2001. Census in brief. Pretoria: Statistics South Africa.

Stow, C. and B. Dodd. 2003. Providing an equitable service to bilingual children in the UK: A review. International Journal of Language and Communication Disorders 38: 351-377.

Strauss, J.P., H.J. van der Linde, S.J. Plekker and J.W.W. Strauss. 1999. Education and manpower development 19. Bloemfontein: University of the Free State. 
Van Dulm, O. and F. Southwood. 2008. Toward a dialect-neutral Afrikaans-medium child language assessment instrument: Test item development. Language Matters 39: 300-315.

Vorster, J. 1980. Toets vir mondelinge taalproduksie [Test for oral language production]. Pretoria: South African Institute for Psychological and Psychometric Research.

Winter, K. 1999. Speech and language therapy provision for bilingual children: Aspects of the current service. International Journal of Language and Communication Disorders 34: 85-98.

Zimmerman, I.L., V.G. Steiner and R.E. Pond. 2011. Preschool language scales. San Antonio: Pearson. 